\title{
An Investigation into the Effective Assessment Practices Use in Large Classes at the University
}

\author{
Shadrack J. Adjogri \\ Department of Chemistry \\ University of Fort Hare, South Africa \\ sadjogri@ufh.ac.za \\ Emmanuel O. Adu \\ School of Continuing and General Education \\ University of Fort Hare, South Africa \\ eadu@ufh.ac.za \\ Olusesan A. Adelabu \\ Department of Microbiology \\ University of Fort Hare, South Africa \\ seccie2003@yahoo.com
}

\section{Doi:10.5901/mjss.2014.v5n6p255}

\begin{abstract}
Management of large classes effectively has been a concern and major phenomenon among higher institution of learning. Large classes give someone the opportunity to improve their teaching and presentation skills while many lecturers that faced with large classes might be tempted to give up, thinking that there is no chance of getting so many students to learn. Therefore the study investigates the effective assessment practices used in large classes at University. Two research questions were asked and answered. Structured questionnaire which was divided into three sections to answer the two research questions were validated and used with the reliability co-efficient of $r=0.87$. The study adopted descriptive survey research design. One hundred and ten lecturers $(N=110)$ were randomly selected from different universities. The results showed that all the indicators mentioned are said to be significant in effective assessment practices in larges classes. It was however recommended that attention should be paid to these indicators so as to facilitate effective assessment practices and teaching in large classes at our universities.
\end{abstract}

Keywords: Large classes, Teaching, Strategies, Exploring, Effective Assessment, Skills, Lecturers

\section{Introduction}

Large classes give someone the opportunity to improve their teaching and presentation skills. Constantly lecturing to a large class - or even a small one - can become boring and bothersome. The value of a large class is that it contains a diversity of students and learning styles and one can use many different, active, and fun ways of teaching. The cumulative knowledge, experiences, skills, and interests of your many students, furthermore, can be valuable starting points for planning lessons and activities so that learning becomes meaningful for your students. In addition, by involving your students' families, you will also have greater access to resources for learning.

During the teaching in a large class, lecturers will be able to improve their evaluation skills as they will devise a variety of ways to tell whether the students have really learned the material, instead of relying only on short answer exams, which may seem necessary for large classes. For instance, you can give your students in-class and out-of-class assignments that ask them what they have learned and what questions they have about what they have learned. Rather than following your students' failures, you can also track their successes, which are also your successes in teaching. You will find also that involving your students in their learning and in assessing how well they have done can save you time and reduce your workload. Your students can also benefit from being in large classes. When there are many students in a class, they can share many different (UNESCO 2006).

There is no single definition of a large class which may generally include 80 students or more. In some cases, 
large may signify a class of 40-70 students, in others, it may include up to 1500 students or more in a single cohort. Large classes are most common in the first year of study at university. This carries the added responsibility of supporting first year students through the transition to university, while also introducing them to learning in the university context.

Many teachers in Asia - and you may be one of them - find themselves working in primary school classrooms that contain many students, sometimes almost filling the room! Actually, though, a large class has no "exact size." Usually it is measured in terms of the number of students per teacher (student-teacher ratio). In some countries, 25-30 students per one teacher is considered large, while in other countries this is seen to be normal or even quite small. From a teacher's perspective, though, a class is "large" whenever it feels large. While a class of more than 50 students is usually considered a large class, to those of you who normally teach 25 or fewer students, a class of 35 can be large and overwhelming. (Dion, 2005)

Similarly, many lecturers that faced with large classes might be tempted to give up, thinking that there is no chance of getting so many students to learn. The problem is, however, that they assume that learning occurs in proportion to class size. The smaller the class, the more students learn. However, research shows that class size does not automatically correlate with student learning. Students in large classes can learn just as well as those in small ones. What counts is not the size of the class, but the quality of the teaching. Evidence shows that students place more emphasis on the quality of teaching than class size. Moreover, they may not mind being in a large class as much as you may think they do, or as much as you mind it yourself (Gibbs 1992)

According to him "I have taught hundreds of students over the span of many years, and my current class has 80 students. At first, I realized that I had finally achieved that comfortable security of having a ready-made set of lecture notes, volumes of exam and quiz questions, and a sense of predictability regarding the course. Strangely enough, however, I was also bored and bothered. Bored from lecturing about the same things year after year, and bothered because my lectures came across so rigidly that I was failing to impart to my students the satisfaction of finding solutions to problems" (Gibbs 1992:13)

Mulligan \& Kirkpatrick, (2000:8). What is valuable to students in large classes including among others the following;

- Give students a short task in the first tutorial to identify students potentially at-risk;

- Provide online support (e.g. discussion forums on the web; course FAQs; self-review quizzes; links to key support sites around the university);

- Develop peer-assisted study programs and mentoring schemes to encourage student interaction; and

- Make the most of small group tutorials for building student confidence and developing connections between students, academic staff and the culture of the Department.

- Build interest and rapport by adopting a relaxed style where students feel comfortable asking questions. Include regular opportunities for students to discuss key points among themselves. Avoid use of humour which may not be understood by students from different cultural or linguistic backgrounds;

- Make the aims of the class explicit and clear. Follow a straightforward progression with a predictable format;

- Pace: vary the pace during sessions to maintain interest (e.g. use a range of media to emphasize key points);

- Explanation and elaboration: give clear explanations of technical terms. Use examples from students' own experiences, cultures and backgrounds. Provide definitions and country-specific terms. Some lecturers ask students to compile glossaries of key terms in groups to assist comprehension;

- Signaling: explicitly identify important information and key concepts. Use clear verbal and written signals when you change topic or emphasis. Avoid relying on tone or intonation alone to signal changes of topic;

- Questioning: create an atmosphere that encourages student questions (e.g. there is no such thing as a stupid question). Repeat questions so that the whole group can hear. Respond empathetically to student questions. Model the question response behaviour that you wish to encourage;

- Visual and multimedia resources: use a range of strategies to enhance student understanding (e.g. graphs, diagrams, movie clips) and give students opportunities to revise material (e.g. PowerPoint's and lecture capture technology).

\subsection{Statement of the problem}

Teaching anything anywhere has its challenges. The common challenge lecturer face is large class sizes. Effective assessment practices to be used become paramount in delivering effective lessons in such a situation. Too many good lecturers have seen their lessons derailed by deficient classroom management skills. Therefore, this study wanted to investigate the effective assessment practices use by lecturers to teach large classes in University. 


\subsection{Research Questions}

The following research questions will be answered to justify the study.

1. What are the effective assessment practices used by lecturers in large classes?

2. Do lecturers possess the skills needed to effectively teach large classes?

\section{Literature Review}

This section looks at the review of literature on teaching effectively in large classes, class size and students' performance and problem with large classes

\subsection{Teaching Effectively in Large Classes}

In large classes, it is very imperative to make the best use of your time and the time available for learning. That is why time management is very essential which means planning in advance. A sizable portion of the work involved in teaching a large class takes place well before the first day of class. For example, in a small class you can more easily give an impulsive assignment, but in a large class you will need more time to carefully plan your lesson and its activities.

Regrettably, many teachers have never been taught how to plan lessons. They were taught to rely on textbooks, in some cases because a textbook is the only available teaching aid. In any case, a good lesson plan will help to relieve your own fears about teaching many students because you will know in advance what you will do, why, and how. You will be able to convey a lesson calmly, and your assurance will carry over to your students who, in turn, will be more restful in learning from you. Even if you rely on a textbook, you must plan how to communicate the information in it so that all of your students will understand. For large classes, this planning is not magnificence; it is a necessity because it will bring order into the classroom environment, even though it may be crowded. (Dion 2005:18)

The planning process centers around three major areas:

- Physical and psycho-social environment, as noted above.

- Content: that is, what topic has been identified in your national curriculum documents, and how can this topic be made meaningful to your students and adapted to fit the local community; and

- Process, or how the content is taught, which may involve using different teaching methods to meet the different learning styles of students or to maximize the time available for teaching and learning.

The following are some of the most important elements in lesson planning that can help you to manage the learning of many students.

\subsubsection{Be comfortable with what you are teaching (topic, content).}

Teaching large classes becomes much more difficult if you are uncertain about what you are teaching. Read up on those topics that you will be covering so that you are confident in presenting them and can maintain a steady focus during your teaching. Your students will be able to follow your lecture and its activities easily, and will be less likely to become bored and disruptive. Think of questions to ask students, and try to anticipate questions that students might ask you. Review the course materials, assignments, and reading lists of other teachers who have taught the topic before. If possible, attend a class taught by an experienced teacher to see how he or she organizes the content and student activities in his or her large class.

\subsubsection{Be clear about why you are teaching this topic and its learning objectives.}

Think about the knowledge, skills, and attitudes you want your students to learn, and choose two or three to focus on in one lesson. Explain clearly to all of your students what you want them to learn from a specific lesson. Some teachers with large classes write the learning objectives on the chalkboard or a large piece of poster paper before class begins. They then explain each objective to their students at the start of the class so everyone has a common understanding of the lesson to be learned.

\subsubsection{Structure your lesson logically.}

The best way to lose students' attention in a large class is to present topics, concepts, and activities in a random manner. 
Some lessons and their content are best presented chronologically, such as historical events, or sequentially in a step-bystep approach (A leads to B which leads to C). At other times, you can describe a problem and then illustrate its solution, or, better yet, have your students work individually or in groups to illustrate how they might solve it.

\subsubsection{Plan your teaching strategy and activities in advance.}

Although you may be tempted to do so, do not plan to lecture for an entire period. Since the attention span of the average student is limited to increments of 10-15 minutes, it is best if you change the format of the lecture every so often so that all of your students will remain attentive. In large classes especially, there is a tendency for students to start talking amongst themselves (or even to fall asleep) when they become bored. Therefore, plan on "mini-lectures" interspersed with brief activities, such as questions and answers or inviting students to share related examples or personal experiences.

In planning your lesson, identify activities in which all of the students can participate in an orderly manner, and select one or, better yet, two teaching methods for each class session: lectures, small group discussions, independent work, role-playing, demonstrations, etc. Decide how you will: (a) prepare the class instruction, (b) present the new concepts, (c) have students apply what they have learned through activities (for example, through discussions, in-class writing activities, or collaborative work), and (e) assess whether students can put into practice what they have learned (for instance, through a short quiz, in class writing assignment, a problem solving exercise, or homework).

While a lot of careful planning is needed to develop an appropriate learning activity, the major reward is better student learning in the large class. To start, instead of asking "What am I going to do in each class session?" focus on "What are my students going to do?" Make sure that whatever activities you choose, students will achieve their learning objectives.

\subsubsection{Recruit teaching assistants in advance.}

While you, as the class teacher, are responsible for your students' learning, you can get others to help you. These "teaching assistants" can be valuable assets to the large class because they will allow you to work with individual students, to manage activities effectively, and to observe the overall class. For instance, ask retired teachers, high school graduates, or parents to help manage your large class or to teach appropriate lessons. They can be particularly valuable in helping your students to conduct group activities. You can even ask older students or the best students in the class to act as peer teachers. Encourage "experts" from the community to be resource persons in classes that talk about special skills and knowledge.

\subsubsection{Pay attention to students with more individualized needs.}

Are there students in your classroom who will need extra help? What kind of support will you need to provide to these students? Do you need to help them on an individual basis, or can other students assist them? Do you need to make sure that they are sitting in an appropriate place in the classroom? Often it helps to have students who need extra help at the front of the classroom where you can easily help them, especially if your classroom is crowded.

\subsubsection{Develop, and follow, a formal lesson plan.}

Good lesson plans achieve at least two objectives. First, they outline what the teacher hopes will occur during a class and, possibly more important, they convey to students that their teacher has thought about the session and its activities. Some of the ways you can plan your lessons well are by using a simple lesson planning outline, daily lesson planning format, or a lesson planning matrix as shown below. Try to use at least one of them in planning your lessons; maybe start with just one topic or lesson. They will give you a firm start in organizing your teaching in a large class setting; a way to monitor whether or not your students are understanding what is taught; and a chance for you to think about what to do next and how to improve your teaching.

\subsubsection{Budget your own time carefully.}

Teaching a large class takes a great deal of time and energy. If you feel rushed or overwhelmed, your students will feel it too. Set up weekly work schedules for yourself so that you are prepared for what needs to be done. Find ways to scale 
back other obligations, if you can, so that you have time to deal with the complexities of teaching such classes

\subsection{Class size and student performance}

The findings of different researches on the relationship between class size and student performance has identified considerable conflicting results (Toth \& Montagna, 2002). The results of some studies show no significant relationship between class size and student performance (Hancock, 1996; Kennedy \& Siegfried, 1997), while other studies favour small class environments (Arias \& Walker, 2004). Results vary based on the criteria or parameters used to measure student performance, as well as the class size evaluate it. When traditional achievement tests are used, small classes provide no advantage over large classes (Kennedy \& Siegfried, 1997). However, if additional performance criteria are used (e.g., long-term retention, problem-solving skills, students' centered approaches etc.), it appears that small classes hold an advantage (Gibbs et al., 1996; Arias \& Walker, 2004).

\subsection{Problems with large classes}

While it is hard to draw definitive conclusions about student achievement based on class size alone, since other variables such as the quality of teachers, student's degree of motivation and the role of the parents may come into play, large classes yield the following difficulties:

- One of the main difficulties that a teacher may experience while teaching a large class is the tremendous effort that she or he will have to make. With an outnumbered class there is always something to be done.

- With a large class, it is difficult to get a satisfactory knowledge of student's needs. Intimacy with students and remembering names might be a problem.

- As a consequence of the large number of students, the noise level is inevitably high which adds to the stress teachers may experience.

- Organizing, planning and presenting lessons may constitute another challenge for teachers in such classes as students' abilities might differ considerably.

- There is another difficulty related to the learning process. In fact, engaging learners actively in the learning process may not be easy in a crowded class.

- It is hard to imagine how a large class would benefit from school resources such as computers, books, references...

- With a crowded classroom, teachers might find it difficulties to measure effectiveness.

- A large class gives reluctant students a place to hide. (Shannon 2006)

\section{Research Methodology}

\subsection{Research Design}

The study adopted descriptive survey research design to investigate the effective assessment practices use by the lecturers to teach in large classes at the Universities.

\subsection{Population/Sample}

The population of this study comprises mainly all the lecturers in some selected universities. Simple random sampling technique was used in the selection of the lecturers. The sample size of this study consists of one hundred and ten university lecturers $(\mathrm{N}=110)$

\subsection{Validity and reliability of research instrument}

A structured questionnaire was used to elicit information from the respondents. The instrument was validated by the experts in the same field and Cronbach alpha was used to measure its reliability. The reliability coefficient is $r=0.87$. The instrument was divided into two section; section 1 required respondents' bio-data, while section 2 contained two parts. Part 1 contains items on effective assessment practices in large classes and part 2 contains items on the required skills 
for teaching large classes. Likert modified response scale was used. The responses range from Strongly Agree Strongly Disagree.

\subsection{Data administration and analyses}

The instrument was administered to the respondents in their various universities with the support of research assistants. The administration was completed in 10 days. Data collected was analyzed using descriptive and Chi-Square statistics

\section{Findings and Discussion}

\subsection{Research question 1: What are the effective assessment practices used by lecturers in large classes?}

Table 1: Descriptive Statistics on Effective Assessment practices in Large Classes

\begin{tabular}{|c|c|c|c|}
\hline ITEMS & $\mathrm{N}$ & Mean & $\begin{array}{c}\text { Std. } \\
\text { Deviation }\end{array}$ \\
\hline I use early assessment strategies and early-warning assessment systems & 110 & 2.2000 & .40183 \\
\hline I adopt front-end assessment: invest time in developing assessment tasks and preparing students for them & 110 & 2.2000 & .40183 \\
\hline I make clear connections between the lecture material and the assessment process & 110 & 2.2000 & .40183 \\
\hline I teach students about strategies for approaching assessment. This might include strategies for planning & 110 & 2.6000 & .49214 \\
\hline I suggest timelines for conducting library research and tips on how to structure their first assignment & 110 & 2.6000 & .49214 \\
\hline I automate assessment tasks where possible (e.g. online quizzes) & 110 & 3.0000 & .89852 \\
\hline I ensure that assessment tasks are kept to a minimum and focus on what really counts & 110 & 2.2000 & .98428 \\
\hline
\end{tabular}

The table 1 above shows the indicators on the effective assessment practices in large classes. The results show that automate assessment tasks where possible (e.g. online quizzes) with (Mean 3.0, SD $=.899$ ) as the best indicator. This is immediately followed by teach students about strategies for approaching assessment and suggest timelines for conducting library research and tips on how to structure their first assignment with (Mean 2.6, and SD of .492) each respectively. While using early assessment strategies and early warning assessment systems and adopting front-end assessment, invest time in developing assessment tasks and preparing students for them and making clear connections between the lecture material and the assessment process were each return (Mean 2.2, and SD of .492) while ensuring that assessment tasks are kept to a minimum and focus on what really counts return (Mean 2.2, and SD of .984).

Table 2: Chi-Square Statistics on Effective Assessment Practices in Large Class

\begin{tabular}{|c|l|c|c|c|c|c|c|c|}
\hline S/N & \multicolumn{1}{|c|}{ ITEMS } & SA & A & D & SD & Df & X.Tab & X.obs \\
\hline 1 & $\begin{array}{l}\text { I use early assessment strategies and early-warning } \\
\text { assessment systems }\end{array}$ & 0 & $22(55.0)$ & $88(55.0)$ & 0 & & \\
\hline 2 & $\begin{array}{l}\text { I adopt front-end assessment: invest time in developing } \\
\text { assessment tasks and preparing students for them }\end{array}$ & 0 & $22(55.0)$ & $88(55.0)$ & 0 & & \\
\hline 3 & $\begin{array}{l}\text { I make clear connections between the lecture material and the } \\
\text { assessment process }\end{array}$ & 0 & $22(55.0)$ & $88(55.0)$ & 0 & 18 & 28.87 & 171.6 \\
\hline 4 & $\begin{array}{l}\text { I teach students about strategies for approaching assessment. } \\
\text { This might include strategies for planning }\end{array}$ & 0 & $66(55.0)$ & $44(55.0)$ & 0 & & \\
\hline 5 & $\begin{array}{l}\text { I suggest timelines for conducting library research and tips on } \\
\text { how to structure their first assignment }\end{array}$ & 0 & $66(55.0)$ & $44(55.0)$ & 0 & & & \\
\hline 6 & $\begin{array}{l}\text { I automate assessment tasks where possible (e.g. online } \\
\text { quizzes) }\end{array}$ & $44(36.70$ & $22(36.7)$ & $44(36.7)$ & 0 & & \\
\hline 7 & $\begin{array}{l}\text { I ensure that assessment tasks are kept to a minimum and } \\
\text { focus on what really counts }\end{array}$ & $22(36.7)$ & 0 & $66(36.7)$ & $22(36.7)$ & & \\
\hline
\end{tabular}

Table 2 revealed the results on the chi-square conducted on the 7 indicators on the effective assessment practices in teaching and managing large classes with $(D f=18, X$. Table Value of 28.87 , and $X$. Observed $=171.6)$. Since the $X$. Observed 171.6 is greater than the $X$. Table Value 28.87; therefore, all the 7 indicators on the effective assessment practices in teaching and managing large classes are said to be significant. 


\subsection{Research question 2: Do lecturers possess the skills needed to effectively teach large classes?}

Table 3: Descriptive statistics on Required Skills for Teaching Large Classes

\begin{tabular}{|l|c|c|c|}
\hline \multicolumn{1}{|c|}{ Items } & $\mathrm{N}$ & Mean & Std. deviation \\
\hline I am skilled in organizing and presenting effective lectures & 110 & 2.2000 & .40183 \\
\hline Engaging students and developing a sense of belonging & 110 & 8.6000 & 12.26407 \\
\hline I am skilled in integrating active learning elements in traditional lecture formats & 110 & 2.6000 & .80366 \\
\hline I am skilled in blending face-to-face and technology-enhanced learning activities & 110 & 2.8000 & .75176 \\
\hline I am skilled in crowd control in large groups & 110 & 2.4000 & .49214 \\
\hline I am sensitive to class climate/mood & 110 & 2.6000 & .49214 \\
\hline I am skilled in managing and supporting staff teams & 110 & 2.2000 & .40183 \\
\hline
\end{tabular}

The table 3 above shows the indicators on the required skills for teaching and managing large classes. The results show that 'engaging students and developing a sense of belonging' is the best indicator with (Mean 8.6, SD = 12.264). This is immediately followed by being skilled in blending face-to-face and technology-enhanced learning activities with (Mean 2.8, and SD of .752); while being skilled in integrating active learning elements in traditional lecture formats with (Mean, 2.6 and SD of .803) and being sensitive to class climate/mood with (Mean, 2.6 and SD of .492) respectively. Other best indicators are skilled in crowd control in large groups with (Mean 2.4, and SD of .492), being skilled in organizing and presenting effective lectures with (Mean, 2.2 and SD of .402), and being skilled in managing and supporting staff teams with (Mean 2.2 and SD of .402).

Table 4: Chi-Square Statistics on Required Skills for Teaching Large Classes

\begin{tabular}{|c|l|c|c|c|c|c|c|c|}
\hline S/N & \multicolumn{1}{|c|}{ ITEMS } & SA & A & D & SD & Df & X.Tab & X.obs \\
\hline 1 & I am skilled in organizing and presenting effective lectures & 0 & $22(55.0)$ & $88(55.0)$ & 0 & & & \\
\hline 2 & Engaging students and developing a sense of belonging & $22(36.7)$ & $44(36.7)$ & $44(36.7)$ & 0 & & \\
\hline 3 & $\begin{array}{l}\text { I am skilled in integrating active learning elements in traditional lecture } \\
\text { formats }\end{array}$ & $22(36.7)$ & $22(36.7)$ & $66(36.7)$ & 0 & 18 & 28.87 & 140.4 \\
\hline 4 & $\begin{array}{l}\text { I am skilled in blending face-to-face and technology-enhanced learning } \\
\text { activities }\end{array}$ & $22(36.7)$ & $44(36.7)$ & $44(36.7)$ & 0 & & \\
\hline 5 & I am skilled in crowd control in large groups & 0 & $44(55.0)$ & $66(55.0)$ & 0 & & & \\
\hline 6 & I am sensitive to class climate/mood & 0 & $22(36.7)$ & $44(55.0)$ & 0 & & & \\
\hline 7 & I am skilled in managing and supporting staff teams & 0 & $22(55.0)$ & $88(55.0)$ & 0 & & \\
\hline
\end{tabular}

Table 4 revealed the results on the chi-square conducted on the 7 indicators on the required skills for teaching and managing large classes with (Df $=18, X$. Table Value of 28.87 , and X. Observed $=140.4$ ). Since the X. Observed 140.4 is greater than the X. Table Value 28.87; therefore, all the 7 indicators on the required skills for teaching and managing large classes are said to be significant.

\section{Conclusion and Recommendation}

Teaching large classes is a challenge and difficult at times, but it can also offer many opportunities for lecturers to improve their teaching and to make it more enjoyable and rewarding for them and their students. The results showed that all the indicators mentioned are said to be significant in teaching larges classes, but 'engaging students and developing a sense of belonging' which was one of the indicators for required skills for teaching large classes is the best indicator with (Mean 8.6, SD = 12.264). Followed by 'automate assessment tasks where possible (e.g. online quizzes)' with (Mean 3.0, $\mathrm{SD}=.899)$ which was under the indicators for effective assessment practices in large class. It was however recommended that attention should be paid to the indicators so as to facilitate effective teaching of large classes in our universities.

\section{References}

Arias, J., \& Walker, D. (2004). Additional evidence on the relationship between class size and student performance. Journal of Economic Education, 4(3), 311-329. 
Dion, L. (2005) "But I Teach a Large Class" in: A Newsletter of the Center for Teaching Effectiveness. University of Delaware. www.udel.edu/pbl/cte/spr96- bisc2.html [accessed online on 10/6/2005]

Gibbs, G. (1992). Improving the quality of student learning. Bristol: Technical and Educational Services.

Gibbs, G., Lucas, L., \& Simonite, V. (1996). Class size and student performance: 1984-94. Studies in Higher Education, 21(3), $261-273$. 20

GIHE (2008). Good Practice Guide on Teaching Large Classes prepared by Dr Lynn Burnett and Professor Kerri-Lee Krause at: www.griffith.edu.au/gihe

Hancock, T. (1996). Effects of class size on college student achievement. College Student Journal, 30(2), 479-481.

Kennedy, P., \& Siegfried, J. (1997). Class size and achievement in introductory economics: Evidence from the TUCE III data. Economics of Education Review, 16(4), 385-394.

Mulligan, D., \& Kirkpatrick, A. (2000). How much do they understand? Lectures, students and comprehension. Higher Education Research and Development, 19(3), 311-335.

Shannon, S. J. (2006). Why don't students attend lectures and what can be done about it through using iPod nanos? In L. Markauskaite, P. Goodyear, \& P. Reimann (Eds.), Australasian Society for Computers in Learning in Tertiary Education (ASCILITE) Conference. Sydney, Australia. [Online]. Available at http://www.ascilite.org.au/conferences/sydney06/proceeding/pdf_papers /p28.pdf.

Stanley, C., \& Porter, E. (Eds.). (2002). Engaging large classes: Strategies and techniques for college faculty. Bolton, MA: Anker Publishing Company.

Toth, L., \& Montagna, L. (2002). Class size and achievement in higher education: A summary of current research. College Student Journal, 36(2), 253-261.

UNESCO (2006) Practical Tips for Teaching Large Classes: A Teacher's Guide. Bangkok. 